\title{
Validation of a French-Canadian version of the Pain Disability Index
}

\author{
Nathalie Gauthier BSc ${ }^{1}$, Pascal Thibault BSc PhD ${ }^{2}$, Heather Adams BSW², Michael JL Sullivan PhD ${ }^{2}$
}

N Gauthier, P Thibault, H Adams, MJL Sullivan. Validation of a French-Canadian version of the Pain Disability Index. Pain Res Manage 2008;13(4):327-333.

OBJECTIVE: To examine the psychometric properties of the Index de l'incapacité reliée à la douleur, a French-Canadian version of the Pain Disability Index (PDI).

METHODS: A total of 176 chronic pain patients (94 women, 82 men) completed the French-Canadian version of the PDI (PDI$\mathrm{CF}$ ), as well as other pain-related measures. A subset of 52 patients (27 women, 25 men) also completed a lifting task designed to assess physical tolerance and pain behaviour.

RESULTS: Confirmatory factor analysis of the PDI-CF supported the two-factor structure of the original PDI. Reliability analyses revealed that the PDI-CF total score had a high degree of internal consistency, comparable with the original PDI. The PDI-CF total score was significantly correlated with self-reported pain, pain catastrophizing, depressive symptoms, fear of movement or (re)injury, lift duration and pain behaviours.

CONCLUSIONS: The results suggest that the PDI-CF is a reliable and valid measure of self-reported disability that is psychometrically similar to the original scale.

Key Words: Chronic pain; Pain Disability Index; Psychometric properties; Risk assessment

A variety of self-report questionnaires have been developed to assess disability associated with pain. The most commonly used self-report measures of pain-related disability include the Roland-Morris Questionnaire (1), the Oswestry Disability Index (2), the Orebro Musculoskeletal Pain Screening Questionnaire (3) and the Pain Disability Index (PDI [4]). On these questionnaires, respondents are asked to make judgments about their ability to successfully complete various domestic, recreational or occupational tasks. The advantage of self-reported measures of pain-related disability is that they are relatively easy to administer and score, thus facilitating their inclusion in research and clinical protocols.

Compared with other self-reported measures of pain-related disability, the PDI is brief, yet comprehensive in the domains of life that it assesses. The PDI assesses the degree to which respondents perceive themselves to be disabled in seven different areas of daily living: home, social, recreational, occupational, sexual, self-care and life support activities. For each domain, respondents are asked to self-report disability ratings on an 11-point scale with the end points 0 (no disability) and

\section{Validation d'une version canadienne-française du Pain Disability Index}

OBJECTIF : Analyser les propriétés psychométriques de l'index de l'incapacité reliée à la douleur, une version canadienne-française du Pain Disability Index (PDI).

MÉTHODES : Cent soixante-seize patients atteints de douleur chronique (94 femmes et 82 hommes) ont répondu à la version canadienne-française du PDI (PDI-CF) et à d'autres questionnaires d'évaluation de la douleur. Une série de 52 patients ( 27 femmes, 25 hommes) ont également effectué une tâche de soulèvement de charge conçue pour évaluer la tolérance physique et le comportement vis-à-vis de la douleur.

RÉSULTATS : L'analyse des facteurs confirmatoires du PDI-CF a appuyé la structure à deux facteurs du PDI original. Les analyses de fiabilité ont révélé que le score total au PDI-CF présentait un degré important de cohésion interne, comparable à celui du PDI original. Le score total au PDI-CF a été en corrélation significative avec la douleur autorapportée, la catastrophisation de l'intensité de la douleur, les symptômes dépressifs, la peur du mouvement ou des blessures ou de leur récurrence, la durée du soulèvement des charges et les comportements face à la douleur.

CONCLUSIONS : Les résultats donnent à penser que le PDI-CF est un outil fiable et valide qui permet aux patients de mesurer leur incapacité et qui est similaire à l'outil de mesure original sur le plan psychométrique.

\footnotetext{
${ }^{1}$ Department of Psychology, Université de Montréal; ${ }^{2}$ Department of Psychology, McGill University, Montreal, Quebec

Correspondence: Dr Michael JL Sullivan, Department of Psychology, McGill University, 1205 Docteur Penfield, Montreal, Quebec H3A 1B1.

E-mailmichael.sullivan@mcgill.ca
} 


\section{TABLE 1}

Original and translated items of the Pain Disability Index (PDI)

PDI items
1. Family or home responsibilities
This category refers to activities related to the home or family. It includes
chores or duties performed around the house (eg, yard work) and errands
or favours for other family members (eg, driving the children to school).

\section{Recreation}

This category includes hobbies, sports and other leisure time activities.

3. Social activity

This category refers to activities which involve participation with friends and acquaintances other than family members. It includes parties, theatre, concerts, dining out and other social functions.

\section{Occupation}

This category refers to activities that are part of or directly related to one's job. This includes nonpaying jobs such as that of a housewife or volunteer work.

5. Sexual behaviour

This category refers to the frequency and quality of one's sex life.

\section{Self-care}

This category includes activities which involve personal maintenance and independent daily living (eg, taking a shower, getting dressed, etc).

\section{Life support activity \\ This category refers to basic life-supporting behaviours such as eating, sleeping and breathing.}

\section{PDI-CF items}

1. Famille / Responsabilités domestiques

Cette catégorie fait allusion aux activités liées à la maison ou à la famille. Elle inclut les tâches ménagères ou les travaux exécutés autour de la maison (par exemple le jardinage) et des commissions ou les services effectués pour des membres de la famille (par exemple conduire les enfants à l'école).

2. Loisirs

Cette catégorie inclut les passe-temps, le sport et les autres loisirs.

3. Activités sociales

Cette catégorie fait allusion aux activités qui impliquent la participation des amis et des connaissances différents des membres de la famille. La catégorie inclut les fêtes, le théâtre, les concerts, dîner au restaurant ainsi que les autres fonctions sociales.

4. Profession

Cette catégorie fait allusion aux activités qui font partie ou sont directement liées à son travail. Cela inclut aussi des activités non rémunérées comme celui d'un travailleur au foyer ou le bénévolat.

5. Activités sexuelles

Cette catégorie fait allusion à la fréquence et à la qualité de sa vie sexuelle.

6. Autonomie

Cette catégorie inclut les activités liées à sa capacité de répondre soi-même à ses besoins personnels et à ses soins quotidiens (par exemple se doucher, s'habiller, etc.)

7. Activités de soutien vital

Cette catégorie fait allusion aux besoins fondamentaux comme manger, dormir et respirer.

PDI-CF French-Canadian version of the PDI

symptoms (5,33-36): fear of pain $(21,36,37)$, catastrophizing (37-39), quality of life (21) and self-reported pain intensity $(30,31,33)$.

To our knowledge, the PDI has only been translated into three other languages: Finnish (27), Swedish (37) and Dutch (36). The availability of a French-Canadian version of the PDI (PDI-CF) could be an important resource for research and practice with French-speaking patients suffering from various pain conditions.

The purpose of the present research was to translate and validate the PDI for use with a French-Canadian population of pain patients. Two studies were undertaken to evaluate the psychometric properties of the PDI-CF. The aim of the first study was to assess factorial structure, internal consistency and correlates of the PDI-CF. The aim of the second study was to assess the relation between the PDI-CF and objective indexes of physical tolerance and pain behaviour.

\section{STUDY 1}

\section{Participants}

A sample of 176 francophone participants (94 women, 82 men) was recruited from private rehabilitation clinics located in the Montreal, Quebec area. All participants were being treated for disability related to a musculoskeletal condition implicating the back or neck. The mean $( \pm$ SD) age of the sample was $41.39 \pm 11.31$ years, and the mean duration of pain was $39.92 \pm 63.43$ months.
Translation

The PDI was first translated into French by two francophone doctoral students working in pain rehabilitation, then backtranslated into English by a professional translator, according to Vallerand's (40) back translation procedures. The accuracy of the translation was evaluated by a comparison of the backtranslated version and the original English version. No major differences emerged from that comparison. The final French version was established following a discussion between the doctoral students and the translator. The original and translated items of the PDI appear in Table 1.

Procedure

All participants completed the PDI-CF before the beginning of an intervention for their musculoskeletal condition. In addition, participants completed a battery of self-report measures including a French-Canadian version of the Pain Catastrophizing Scale (PCS-CF [41]), a French-Canadian version of the Tampa Scale for Kinesophobia (TSK-CF [42]), a French version of the Beck Depression Inventory II (BDI-II-F [43]) and a French-Canadian version of the McGill Pain Questionnaire (MPQ-CF [44]).

\section{Measures}

Catastrophizing: The PCS (45) consists of 13 items describing different thoughts and feeling related to pain. The PCS-CF has been shown to be internally reliable (coefficient $\alpha=0.91$ ) and 
TABLE 2

Sample characteristics

\begin{tabular}{lccc}
\hline Characteristic & Women $(\mathbf{n = 9 4})$ & Men $(\mathbf{n = 8 2})$ & $\mathbf{P}$ \\
\hline Age (years) & $41.9 \pm 11.8$ & $40.8 \pm 10.8$ & $\mathrm{~ns}$ \\
Pain duration (months) & $41.4 \pm 70.0$ & $38.2 \pm 55.3$ & $\mathrm{~ns}$ \\
PDI-CF & $36.1 \pm 14.7$ & $34.3 \pm 12.8$ & $\mathrm{~ns}$ \\
PCS-CF & $26.2 \pm 12.2$ & $24.1 \pm 12.1$ & $\mathrm{~ns}$ \\
TSK-CF & $42.7 \pm 8.8$ & $45.5 \pm 8.5$ & 0.035 \\
BDI-II-F & $19.6 \pm 10.6$ & $19.2 \pm 14.2$ & $\mathrm{~ns}$ \\
MPQ-CF-PRI & $31.1 \pm 13.7$ & $28.0 \pm 13.0$ & $\mathrm{~ns}$
\end{tabular}

Data presented as mean \pm SD. BDI-II-F Beck Depression Inventory II, French version; MPQ-CF-PRI McGill Pain Questionnaire Pain Rating Index, FrenchCanadian version; ns Nonsignificant; PCS-CF Pain Catastrophizing Scale, French-Canadian version; PDI-CF Pain Disability Index, French-Canadian version; TSK-CF Tampa Scale for Kinesophobia, French-Canadian version

to be associated with a variety of pain-related outcomes (41). Fear of movement or (re)injury: The TSK (46) is a 17-item questionnaire that assesses fear of injury due to movement. The TSK-CF has been shown to be internally reliable (coefficient $\alpha=0.71$ ). The TSK has been associated with various indexes of behavioural avoidance (47).

Depression: The BDI-II (43) is a commonly used self-reported measure of depression. The BDI-II has been shown to be a reliable (coefficient $\alpha=0.84$ ) (48) and valid index of depressive symptoms in chronic pain patients and primary care medical patients $(33,48,49)$.

Pain severity: The MPQ (50) is a useful index of pain severity. The Pain Rating Index of the MPQ-CF (MPQ-CF-PRI) consists of 20 groupings of adjectives describing pain experience. The PRI is considered one of the more reliable and valid indexes of an individual's pain experience (51).

\section{Results}

Sample characteristics: Means $( \pm$ SD) for sample demographics and pain-related questionnaires are presented in Table 2. Scores on measures of self-reported disability, depression, catastrophizing, fear of pain or (re)injury and pain intensity are comparable with those that have been reported in previous research in chronic pain patients (52). Men reported more fear of pain or (re)injury than women, $t(172)=-2.13, \mathrm{P}=0.035$. No other sex differences were found.

Scale characteristics: The mean score for the PDI-CF was 35.27 , with a range of 0 to 65 . Scores were normally distributed ( skewness $=-0.084$, kurtosis $=-0.443$ ). These data generally conform to those previously reported with the original PDI $(1,23)$.

To assess the internal consistency of the questionnaire, an alpha reliability coefficient was computed for the seven items of the scale. An alpha coefficient of 0.83 was obtained, indicating a good internal consistency (53). Item-total correlations varied from 0.57 to 0.80 .

Factor structure: Based on previous research on the factor structure of the PDI, two alternative models were evaluated for goodness-of-fit. The test of the goodness-of-fit of the factor structure was conducted by means of confirmatory factor analyses using the Amos statistical software package (SPSS Inc, USA) (54). Goodness-of-fit was evaluated using multiple criteria: $\chi^{2}$ value, the comparative fit index (CFI), the nonnormed fit index (NNFI) and root mean square error of
TABLE 3

Goodness-of-fit indexes for confirmatory factor analyses of two alternative models of the Pain Disability Index

\begin{tabular}{lccccc}
\hline Model & $\chi^{2}$ & df & CFI & NNFI & RMSEA (90\% CL) \\
\hline Model 1 & 48.0 & 14 & 0.918 & 0.877 & $0.118(0.082-0.155)$ \\
Model 2 & 29.9 & 13 & 0.959 & 0.934 & $0.086(0.045-0.127)$ \\
\hline
\end{tabular}

Model 1 is the one-factor model of reference 24 . Model 2 is the two-factor model of reference 23. CFI Comparative fit index; CL Confidence level; df Degrees of freedom; NNFI Non-normative fit index; RMSEA Root mean square error of approximation

\section{TABLE 4}

Correlates of disability

\begin{tabular}{|c|c|c|c|c|c|c|c|c|}
\hline & Home & Social & Recre & Occup & Sex & Self & Life & Total \\
\hline PCS-CF & $0.35^{\star *}$ & ${ }^{*} 0.22^{\star *}$ & $0.45^{\star *}$ & $0.30^{* *}$ & $0.40^{* *}$ & $0.34^{* *}$ & $0.42^{\star *}$ & $0.51^{\text {** }}$ \\
\hline TSK-CF & $0.37^{\star *}$ & ${ }^{*} 0.28^{* *}$ & $0.38^{* *}$ & $0.36^{\star \star}$ & $0.43^{\star *}$ & $0.25^{* *}$ & $0.34^{\star *}$ & $0.49^{* *}$ \\
\hline BDI-II-F & 0.15 & 0.19 & $0.35^{\star *}$ & $0.27^{\star *}$ & $0.41^{* *}$ & 0.17 & $0.26^{*}$ & $0.35^{\star *}$ \\
\hline $\begin{array}{c}\text { MPQ-CF- } \\
\text { PRI }\end{array}$ & $0.31^{* *}$ & ${ }^{*} 0.18^{*}$ & $0.25^{\star *}$ & $0.25^{* *}$ & $0.33^{\star *}$ & $0.31^{* *}$ & $0.36^{\star *}$ & $0.43^{* *}$ \\
\hline
\end{tabular}

Pain Disability Index, French-Canadian version (PDI-CF) subscales: Home $=$ home maintenance activities; Social = social activities; Recre = recreational activities; Occup = occupational activities; Sex = sexual activities; Life = lifesupport activities; Total = total PDI-CF score. BDI-II-F Beck Depression Inventory II, French version; MPQ-CF-PRI McGill Pain Questionnaire Pain Rating Index, French-Canadian version; PCS-CF Pain Catastrophizing Scale, French-Canadian version; TSK-CF Tampa Scale for Kinesophobia, FrenchCanadian version. ${ }^{*} P<0.05,{ }^{* *} P<0.01$

approximation (RMSEA). For the RMSEA, values below 0.08 indicate adequate fit, while values below 0.05 represent good fit. For both the CFI and the NNFI, values above 0.90 indicate good fit. Table 3 summarizes the goodness-of-fit indexes for each of the two models.

Consistent with research on the factor structure of the original PDI, confirmatory factor analysis suggested that the twofactor model of Tait et al (23) provided the best fit to the data (RMSEA=0.09, CFI=0.96, NNFI=0.93). Comparison of the two-factor model with a one-factor model revealed that the goodness-of-fit of the two-factor solution was significantly better than that of the single-factor solution $\left(\Delta \chi^{2}[1]=18.1\right.$, $\mathrm{P}<0.001)$.

Correlates of disability: Correlations between measures of catastrophizing, depression, fear of pain or (re)injury, pain intensity, and the seven items of the PDI-CF are presented in Table 4.

Measures of catastrophizing, fear of movement or (re)injury, and pain intensity were significantly correlated with all the items and the total scores of the PDI-CF. The score on the BDI-II-F was significantly associated with the total score on the PDI-CF, but some correlations with individual items were nonsignificant.

\section{Discussion}

Study 1 replicated the factorial structure found in previous research, that is, the two-factor model of the PDI (21-23). The present study also found the same level of internal consistency as the original PDI $(5,21-25)$. Correlations with the PCS-CF, TSK-CF, BDI-II-F and MPQ-CF-PRI also support the construct validity of the PDI-CF. The results of study 1 suggest that PDI-CF is a valid and reliable measure of self-reported disability. 


\section{STUDY 2}

A second study was conducted to evaluate the relation between scores on the PDI-CF and objective indexes of physical tolerance and pain behaviour. Previous studies have demonstrated significant relations between scores on the original PDI and various measures of disability, such as maximum amount of weight lifted during a floor-to-waist lift $(29,30,33)$, performance in exercise bouts involving manoeuvres such as sit-ups, arch-ups or squatting $(27,28)$. One objective of study 2 was to determine if the scores on the PDI-CF were associated with a physical performance measure.

The relation between scores on the PDI-CF and pain behaviour was also examined. Pain behaviours can be defined as actions or postural displays enacted during the experience of pain $(55,56)$. Previous research using the original PDI has shown that self-reported pain-related disability is associated with observed pain behaviours $(22,31)$.

\section{Participants}

A subsample of 52 francophone participants (27 women, 25 men) was drawn from the sample of study 1 . An initial screening was made by a physician or an occupational therapist to identify and exclude participants with a medical condition that may be adversely affected by the lifting task. The mean age of the sample was $45.67 \pm 11.45$ years. The mean duration of pain was $59.95 \pm 90.42$ months.

\section{Procedure}

In addition to completing the pain-related measures (PCS-CF, TSK-CF, BDI-II, MPQ-CF), participants were invited to participate in a lifting task modelled after Butler and Kozey (57). A detailed description of this procedure can be found in Sullivan et al (58).

Participants were asked to stand in front of a table adjusted to waist height (surface area $80 \mathrm{~cm} \times 120 \mathrm{~cm}$ ), on which 18 canisters ( $4 \mathrm{~L}$ paint canisters) were placed that were partially filled with sand. The canisters weighed $2.9 \mathrm{~kg}, 3.4 \mathrm{~kg}$ or $3.9 \mathrm{~kg}$ and were arranged in three rows of six canisters. The selection of loads was based on research suggesting a $12 \%$ weight difference for detection threshold and National Institute for Occupational Safety and Health recommendations for safe weight limits $(59,60)$.

The different weight canisters were positioned such that each weight was represented twice in each location of a double Latin square. The participant was asked to lift each canister in turn according to a predetermined sequence. The task was designed such that the forward flexion and arm extension required to lift canisters further away from the body would increase the loading on the cervical and lumbar portions of the spine, momentarily increasing discomfort (61).

The participants were asked to perform three different tasks: lifting tolerance, weight estimation and pain rating. The lifting tolerance task was always the first task performed by the participant. The order of the weight estimation task and the pain rating task was counterbalanced across participants.

Lifting tolerance task: In the lifting tolerance task, participants were asked to lift a canister in the third position (ie, furthest away from the body) and hold the canister with the arm fully extended as long as he or she was able. The lifting tolerance task was used as an index of physical disability. The assumption underlying this measure is that individuals who have high levels of self-reported disability will perform worse than those with a low level of disability. Physical tolerance was operationally defined as the total time that the canister was held off the surface of the table.

Weight estimation task: In the weight estimation task, participants were asked to lift canisters in a predetermined sequence (ie, column 1, first, second, third position; column 2, first, second, third position; etc). Participants were asked to estimate the weight of each canister.

Pain rating task: In the pain rating task, participants lifted the same canisters in the same sequence as they were lifted in the weight estimation task. Participants were asked to provide a verbal rating of their pain as they lifted each canister, on an 11 point scale with the end points 0 (no pain) and 10 (extreme pain).

Participants were videotaped throughout the procedure. A camera positioned at a $45^{\circ}$ angle to the table afforded a threequarter view of the face, trunk and upper extremities of the participant. A research assistant sat approximately $2 \mathrm{~m}$ in front of the table. The ostensible purpose of the research assistant was to record the participants' weight estimates and pain ratings. The camera was positioned beside the research assistant to maximize the probability that the face would be visible to the camera when the participant reported his or her ratings to the research assistant.

\section{Pain behaviour coding}

Two trained coders, blind to experimental hypotheses, independently coded each video record for instances of pain behaviour. The assessment of pain behaviour included all major dimensions of pain behaviour described in the Keefe and Block system (62). Coders were trained to competency using a pain behaviour coding manual.

Each video record was divided into 18 different segments (ie, cycles) corresponding to the lift of each different canister. A cycle was defined as the period starting with the participant touching the handle of one canister and ending with the moment the participant touched the handle of the next canister. For each cycle, the duration and intensity of pain behaviours was recorded. Pain behaviours were classified as communicative pain behaviours or protective pain behaviours. Communicative pain behaviours included facial expressions such as grimacing or wincing, and verbal or paraverbal pain expressions such as pain words, grunts, sighs and moans. Protective pain behaviours included active movements such as guarding, holding, touching or rubbing as well as passive behaviours such as avoidance. For each pain behaviour, coders provided intensity ratings on a three-point scale with the following anchors: mild, moderate and intense. Indexes of pain behaviour were computed for each cycle by multiplying the duration of pain behaviour by the intensity of the pain behaviour (63). Because the authors were only interested in the relation between self-reported disability and pain behaviours, pain behaviours were summed across different weight canisters and different positions, removing these factors from the design of analysis of pain behaviours. Separate scores were derived for communicative and protective pain behaviours. An overall estimated weight score was obtained by averaging all weight estimates provided during the weight estimation portion of the task. An overall pain score was obtained by averaging all pain ratings provided during the pain rating portion of the task. 


\section{Results}

To evaluate how self-report disability reflects the actual level of disability, correlation analyses were performed between the total score on the PDI-CF and the lift duration. Results showed that scores on the PDI-CF were significantly correlated with lift duration $(\mathrm{r}=-0.415, \mathrm{P}=0.002)$, indicating that participants with high levels of self-reported disability lifted the canister for a shorter period of time than individuals with lower scores of the same measure. Scores on the PDI-CF were also significantly related to the occurrence of pain behaviours. Specifically, self-reported disability was associated with greater expression of communicative pain behaviours (eg, grimacing or wincing) $(\mathrm{r}=0.29, \mathrm{P}=0.038)$, and protective pain behaviours (eg, rubbing or guarding) $(\mathrm{r}=0.29, \mathrm{P}=0.037)$. A significant correlation was obtained between scores on the PDI-CF and overall pain ratings $(\mathrm{r}=0.48, \mathrm{P}<0.001)$. The correlation between scores on PDI-CF and overall weight estimates was not significant $(\mathrm{r}=0.18, \mathrm{P}=0.206)$.

\section{Discussion}

The results of study 2 indicate that scores on the PDI-CF are significantly correlated with objective indexes of disability. Higher scores on the PDI-CF were associated with shorter lift duration during the lifting tolerance component of the physical performance task. These findings are consistent with those of Gross and Battié (64), who reported a correlation of -0.55 $(\mathrm{P}=0.05)$ between the original PDI and the maximum amount of weight lifted during a floor-to-waist lift.

The PDI-CF also correlated with measures of pain behaviour. Higher scores on the PDI-CF were associated with more pronounced displays of communicative and protective pain behaviours. These findings are consistent with McCahon et al (31), who reported a correlation of $0.54(\mathrm{P}<0.0005)$ between the original PDI total score and total pain behaviour score.

\section{GENERAL DISCUSSION}

The present study had the objective of assessing the content validity, internal consistency and correlates of the PDI-CF in a sample of chronic pain patients. A two-factor structure emerged, which contained items related to voluntary or obligatory activities. Our results showed that both the reliability and the internal consistency of the scale were excellent, and that the scale was comparable to the original scale developed by Pollard (4).

Our results also demonstrated that the score on the PDI-CF is associated with the scores on many validated French painrelated questionnaires, such as the TSK-CF, BDI-II-F, PCS-CF and MPQ-CF-PRI. As indicated earlier, other researchers have also observed these relations with the original PDI. High scores on the PDI-CF constitute an indication of the potential presence of other psychosocial factors that can contribute to the disability experience.

The PDI-CF total score was also associated with lift duration, indicating that the reported level of disability constitutes a fair approximation of the actual level of disability in a physical task. In addition, the PDI-CF total score was associated with pain behaviours. As Turk and Flor (65) suggested, selfreporting a disability can be viewed as a 'covert' pain behaviour because it is the only possible way to be aware of the internal processes concerning the patients' perception of their disability and physical limitations. Pain behaviours may be conceptualized as a channel through which pain patients can communicate their disability level to others.
One limitation of the present study is that the sample used was recruited from pain clinics, and was constituted of individuals who suffered from chronic pain due to a musculoskeletal condition. These individuals may have responded differently from other individuals who suffer from pain but are not actually receiving treatment. In addition, the sample used in the present study consisted of chronic pain patients who were probably treatment-resistant. Indeed, the mean duration of pain in study 1 was approximately three years, and in study 2 , approximately five years. It is not clear whether the same relations would emerge in samples of patients with acute or subacute pain. Also, this French language validation was conducted in Quebec, Canada. The extent to which the results generalize to other French-speaking communities or countries cannot be assumed. These considerations have implications for the generalization of the findings.

Despite these limitations, the brevity, ease of administration and good psychometrics properties of the PDI-CF suggests that it might prove to be a useful instrument in research and clinical settings. As a screening questionnaire, the PDI-CF could be used to identify patients with high levels of painrelated disability. Previous research demonstrated that high scores on self-reported disability measures were associated with other psychosocial risk factors for chronicity following injury. Therefore, researchers and clinicians could use the score on the PDI-CF as a cue to investigate other psychosocial risk factors, allowing for intervention that will directly address factors that are important for the rehabilitation of a given individual. As a tracking measure, the PDI-CF could be used to facilitate evidence-based medical decision making. When administered on a periodical basis, the PDI-CF tracks slow recovery and potential problems in the rehabilitation process. Patients with high levels of self-reported disability after a reasonable recovery time could be screened and identified to receive treatment that will focus more specifically on problematic areas.

\section{CONCLUSION}

The PDI-CF may constitute a welcome addition to the tools that francophone clinicians and researchers currently possess to assess and treat patients who experience pain-related limitations.

ACKNOWLEDGEMENTS: The authors thank André Savard, Dorothée Ialongo Lambin and Marc-Olivier Martel for their assistance with data collection. Portions of this research were presented at the Annual Meeting of the Canadian Pain Society, Edmonton, Canada, 2006. Parts of this research were supported by grants from the Canadian Institutes of Health Research and the Social Sciences and Humanities Research Council of Canada.

\section{REFERENCES}

1. Roland M, Morris R. A study of the natural history of back pain. Part I: Development of a reliable and sensitive measure of disability in low-back pain. Spine 1983;8:141-4.

2. Fairbank JC, Pynsent PB. The Oswestry Disability Index. Spine 2000;25:2940-52.

3. Linton SJ, Hallden K. Risk factors and the natural course of acute and recurrent musculoskeletal pain: Developing a screening instrument. Proceedings of the 8th World Congress on Pain. Vancouver, August 17 to 22, 1996.

4. Pollard C. Preliminary validity study of the Pain Disability Index. Percept Mot Skills 1984;59:974.

5. Geisser ME, Roth RS, Theisen ME, Robinson ME, Riley JL III. Negative affect, self-report of depressive symptoms, and clinical depression: Relation to the experience of chronic pain. Clin J Pain 2000;16:110-20. 
6. Moulin DE, Iezzi A, Amireh R, Sharpe WK, Boyd D, Merskey H. Randomised trial of oral morphine for chronic non-cancer pain. Lancet 1996;347:143-7.

7. Rittweger J, Just K, Kautzsch K, Reeg P, Felsenberg D. Treatment of chronic lower back pain with lumbar extension and whole-body vibration exercise: A randomized controlled trial. Spine 2002;27:1829-34

8. Simpson RK Jr, Edmondson EA, Constant CF, Collier C. Transdermal fentanyl as treatment for chronic low back pain. J Pain Symptom Manage 1997;14:218-24.

9. Lemstra M, Olszynski WP. The effectiveness of multidisciplinary rehabilitation in the treatment of fibromyalgia: A randomized controlled trial. Clin J Pain 2005;21:166-74.

10. Narin SO, Pinar L, Erbas D, Oztürk V, Idiman F. The effects of exercise and exercise-related changes in blood nitric oxide level on migraine headache. Clin Rehabil 2003;17:624-30.

11. Petrak F, Hardt J, Kappis B, Nickel R, Tiber Egle U. Determinants of health-related quality of life in patients with persistent somatoform pain disorder. Eur J Pain 2003;7:463-71.

12. Söderlund A, Lindberg P. Whiplash-associated disorders predicting disability from a process-oriented perspective of coping Clin Rehabil 2003;17:101-7.

13. Turk DC, Sist TC, Okifuji A, et al. Adaptation to metastatic cancer pain, regional/local cancer pain and non-cancer pain: Role of psychological and behavioral factors. Pain 1998;74:247-56.

14. Bishop SR, Warr D. Coping, catastrophizing and chronic pain in breast cancer. J Behav Med 2003;26:265-81.

15. Eisenberg E, Lurie Y, Braker C, Daoud D, Ishay A. Lamotrigine reduces painful diabetic neuropathy: A randomized, controlled study. Neurology 2001;57:505-9.

16. Harke H, Gretenkort P, Ladleif HU, Koester P, Rahman S. Spinal cord stimulation in postherpetic neuralgia and in acute herpes zoster pain. Anesth Analg 2002;94:694-700.

17. Kerschan K, Alacamlioglu Y, Kollmitzer J, et al. Functional impact of unvarying exercise program in women after menopause. Am J Phys Med Rehabil 1998;77:326-32.

18. Bush FM, Harkins SW. Pain-related limitation in activities of daily living in patients with chronic orofacial pain: Psychometric properties of a disability index. J Orofac Pain 1995;9:57-63.

19. Durham RM, Mistry BM, Mazuski JE, Shapiro M, Jacobs D. Outcome and utility of scoring systems in the management of the mangled extremity. Am J Surg 1996;172:569-73.

20. Katz J, Cohen L. Preventive analgesia is associated with reduced pain disability 3 weeks but not 6 months after major gynecologic surgery by laparotomy. Anesthesiology 2004;101:169-74.

21. Tait RC, Chibnall JT. Factor structure of the pain disability index in workers compensation claimants with low back injuries. Arch Phys Med Rehabil 2005;86:1141-6.

22. Tait RC, Chibnall JT, Krause S. The Pain Disability Index: Psychometric properties. Pain 1990;40:171-82.

23. Tait RC, Pollard CA, Margolis RB, Duckro PN, Krause SJ. The Pain Disability Index: Psychometric and validity data. Arch Phys Med Rehabil 1987;68:438-41

24. Chibnall JT, Tait RC. The Pain Disability Index: Factor structure and normative data. Arch Phys Med Rehabil 1994;75:1082-6.

25. Strong J, Ashton R, Large RG. Function and the patient with chronic low back pain. Clin J Pain 1994;10:191-6.

26. Gauthier N, Sullivan MJL, Adams H, Stanish WD, Thibault P. Investigating risk factors for chronicity: The importance of distinguishing between return-to-work status and self-report measures of disability. J Occup Environ Med 2006;48:312-8.

27. Gronblad M, Hurri H, Kouri JP. Relationships between spinal mobility, physical performance tests, pain intensity and disability assessments in chronic low back pain patients. Scand J Rehabil Med 1997;29:17-24

28. Grönblad M, Järvinen E, Hurri H, Hupli M, Karaharju EO. Relationship of the Pain Disability Index (PDI) and the Oswestry Disability Questionnaire (ODQ) with three dynamic physical tests in a group of patients with chronic low-back and leg pain. Clin J Pain 1994;10:197-203.

29. Gross DP, Battié MC. Construct validity of a kinesiophysical functional capacity evaluation administered within a worker's compensation environment. J Occup Rehabil 2003;13:287-95.

30. Gross DP, Battié MC. Factors influencing results of functional capacity evaluations in workers' compensation claimants with low back pain. Phys Ther 2005;85:315-22.
31. McCahon S, Strong J, Sharry R, Cramond T. Self-report and pain behavior among patients with chronic pain. Clin J Pain 2005;21:223-31.

32. Sullivan MJL, Ward LC, Tripp D, French DJ, Adams H, Stanish WD. Secondary prevention of work disability: Communitybased psychosocial intervention for musculoskeletal disorders. J Occup Rehabil 2005;15:377-92.

33. Vowles KE, Gross RT, Sorrell JT. Predicting work status following interdisciplinary treatment for chronic pain. Eur J Pain 2004;8:351-8

34. Auerbach SM, Laskin DM, Frantsve LM, Orr T. Depression, pain, exposure to stressful life events, and long-term outcomes in temporomandibular disorder patients. J Oral Maxillofac Surg 2001;59:628-33

35. Türp JC, Kowalski CJ, Stohler CS. Greater disability with increased pain involvement, pain intensity and depressive preoccupation. Eur J Pain 1997;1:271-7.

36. Samwel HJ, Evers AW, Crul BJ, Kraaimaat FW. The role of helplessness, fear of pain, and passive pain-coping in chronic pain patients. Clin J Pain 2006;22:245-51.

37. Denison E, Asenlöf P, Lindberg P. Self-efficacy, fear avoidance, and pain intensity as predictors of disability in subacute and chronic musculoskeletal pain patients in primary health care. Pain 2004:111:245-52.

38. Sullivan MJ, Stanish W, Waite H, Sullivan M, Tripp DA. Catastrophizing, pain, and disability in patients with soft-tissue injuries. Pain 1998;77:253-60.

39. Sullivan MJ, Sullivan ME, Adams HM. Stage of chronicity and cognitive correlates of pain-related disability. Cogn Behav Ther 2002;31:111-8

40. Vallerand RJ. [Toward a methodology for the transcultural validation of psychological questionnaires: Implications for research in the French language.] Can Psychol 1989;30:662-80.

41. French DJ, Noel M, Vigneau F, French JA, Cyr CP, Evans R. [PCS-CF: A French-language, French-Canadian adaptation of the Pain Catastrophizing Scale.] Can J Behav Sci 2005;37:181-92.

42. French DJ, Roach PJ, Mayes S. Peur du mouvement chez des accidentés du travail: l'Échelle de Kinésiophobie de Tampa (EKT). Can J Behav Sci 2002:34:28-33.

43. Beck AT, Brown GK, Steer RA. Beck Depression Inventory II manual. San Antonio: Psychological Corporation, 1996.

44. Veilleux S, Sicard D, Bohuon A. Traduction du McGill Pain Questionnaire. In: Melzack R, Wall PD, eds. Le Défi de la Douleur. Troisième édition entièrement refondue. Edisem: St-Hyacinthe, 1989:290.

45. Sullivan MJ, Bishop SR, Pivik J. The Pain Catastrophizing Scale: Development and validation. Psychol Assess 1995;7:524-32.

46. Kori SH, Miller RP, Todd DD. Kinesophobia: A new view of chronic pain behavior. Pain Manag 1990;3:35-43.

47. Crombez G, Vlaeyen JW, Heuts PH, Lysens R. Pain-related fear is more disabling than pain itself: Evidence on the role of pain-related fear in chronic back pain disability. Pain 1999;80:329-39.

48. Arnau RC, Meagher MW, Norris MP, Bramson R. Psychometric evaluation of the Beck Depression Inventory-II with primary care medical patients. Health Psychol 2001;20:112-9.

49. Bishop SR, Edgley K, Fisher R, Sullivan MJ. Screening for depression in chronic low back pain with the Beck Depression Inventory. Can J Rehabil 1993;7:143-8.

50. Melzack R. The McGill Pain Questionnaire: Major properties and scoring methods. Pain 1975;1:277-99.

51. Turk DC, Rudy TE, Salovey P. The McGill Pain Questionnaire reconsidered: Confirming the factor structure and examining appropriate uses. Pain 1985;21:385-97.

52. Sullivan MJ, Adams H, Thibault P, Corbière M, Stanish WD. Initial depression severity and the trajectory of recovery following cognitive-behavioral intervention for work disability. J Occup Rehabil 2006;16:63-74.

53. George D, Mallery P. SPSS for Windows Step by Step: A Simple Guide and Reference, 12.0 update, 5th edn. New Zealand: Allyn \& Bacon, 2005

54. Arbuckle JL, Wothke W. Amos 4.0 User's Guide. Chicago: Smallwaters Corporation, 1999.

55. Fordyce WE. Behavioral Methods for Chronic Pain and Illness. St Louis: Mosby, 1976.

56. Keefe FJ, Dunsmore J. Pain behavior: Concepts and controversies. Am Pain Soc J 1992;1:92-100. 
57. Butler HL, Kozey JW. The effect of load and posture on load estimations during a simulated lifting task in female workers. Int J Ind Ergon 2003;31:331-41.

58. Sullivan MJL, Thibault P, Savard A, Catchlove R, Kozey J, Stanish WD. The influence of communication goals and physical demands on different dimensions of pain behavior. Pain 2006;125:270-7.

59. Karwowski W, Shumate C, Yates J, Pongpatana N. Discriminability of load heaviness: Implications for the psychophysical approach to manual lifting. Ergonomics 1992;35:729-44.

60. Waters T, Putz-Anderson V, Garg A, Fine L. Revised NIOSH equation for the design and evaluation of manual lifting tasks. Ergonomics 1993;36:749-76.
61. Tsuang YH, Schipplein OD, Trafimow JH, Andersson GB. Influence of body segment dynamics on loads at the lumbar spine during lifting. Ergonomics 1992;35:437-44.

62. Keefe FJ, Block AR. Development of an observation method for assessing pain behavior in chronic low back pain patients. Behav Ther 1982;13:363-75.

63. Prkachin KM, Schultz I, Berkowitz J, Hughes E, Hunt D. Assessing pain behaviour of low-back pain patients in real time: Concurrent validity and examiner sensitivity. Behav Res Ther 2002;40:595-607.

64. Gross DP, Battié MC. Functional capacity evaluation performance does not predict sustained return to work in claimants with chronic back pain. J Occup Rehabil 2005;15:285-94.

65. Turk DC, Flor H. Pain greater than pain behaviors: The utility and limitations of the pain behavior construct. Pain 1987;31:277-95. 


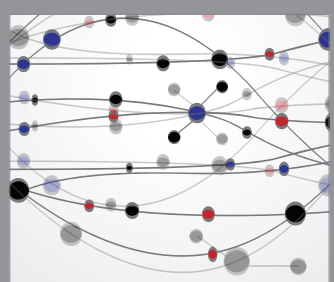

The Scientific World Journal
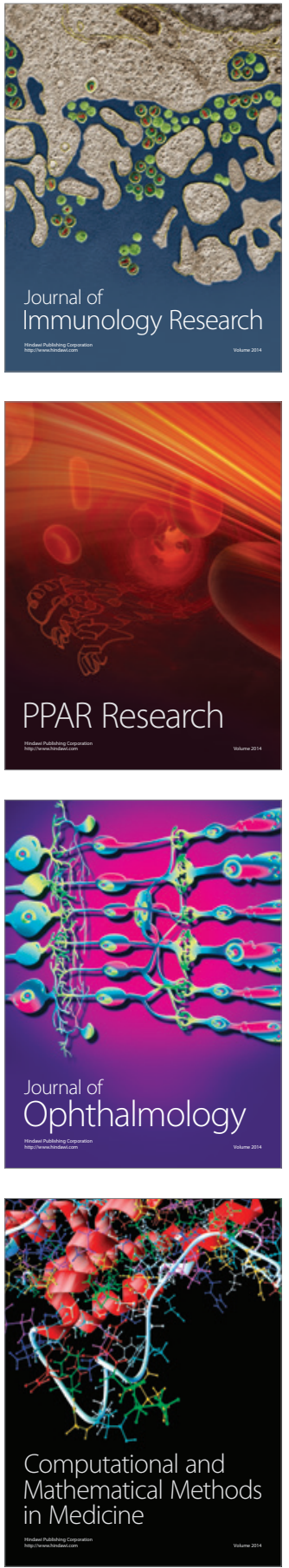

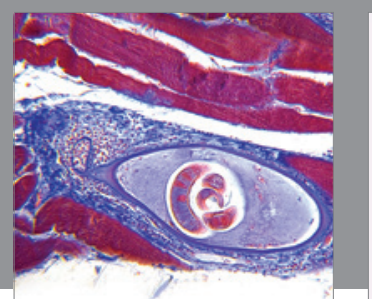

Gastroenterology Research and Practice

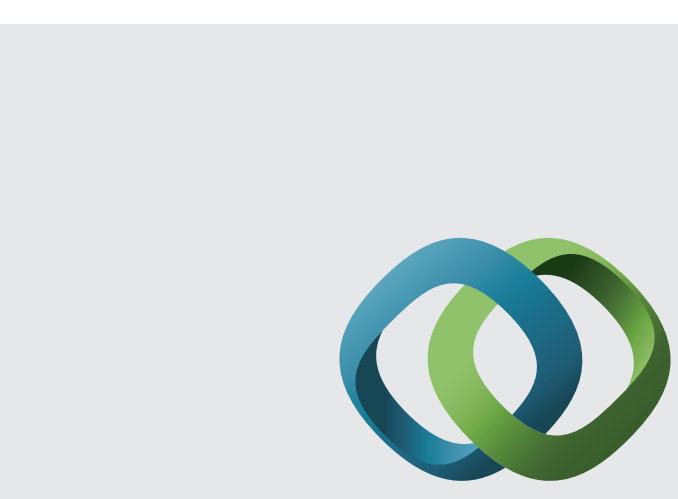

\section{Hindawi}

Submit your manuscripts at

http://www.hindawi.com
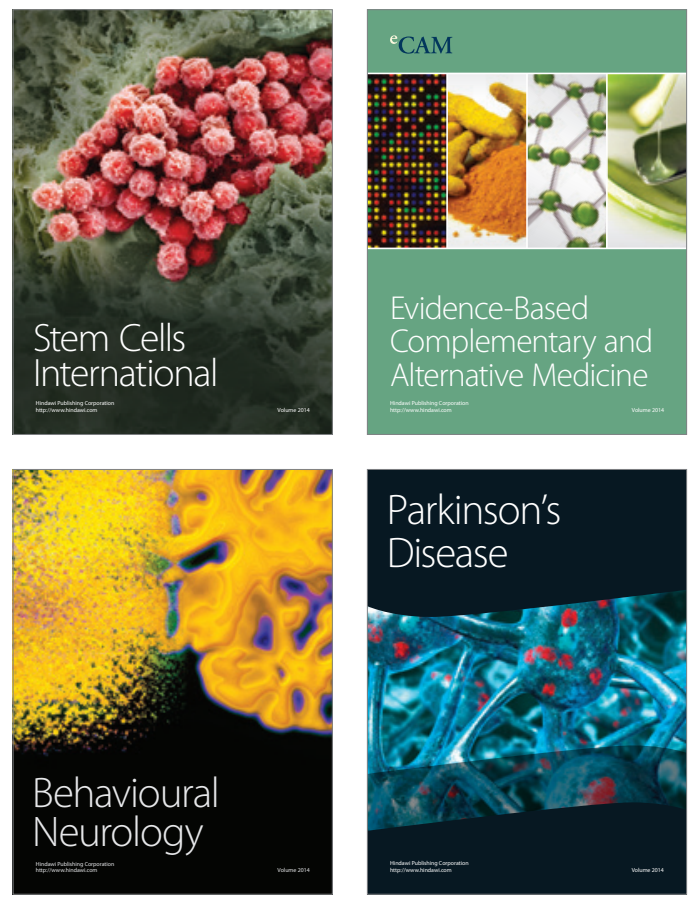
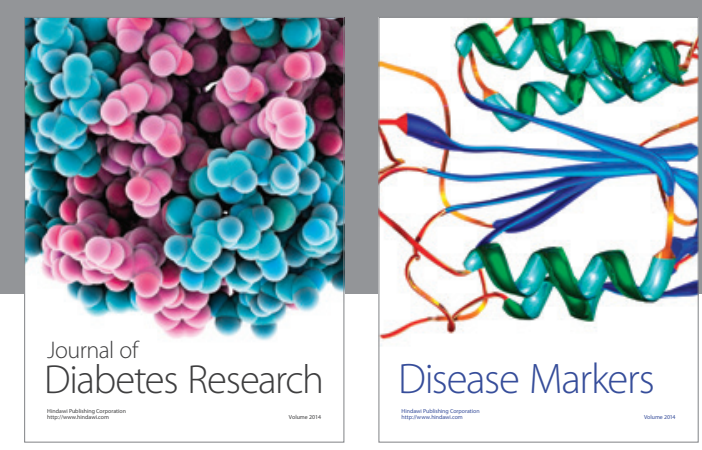

Disease Markers
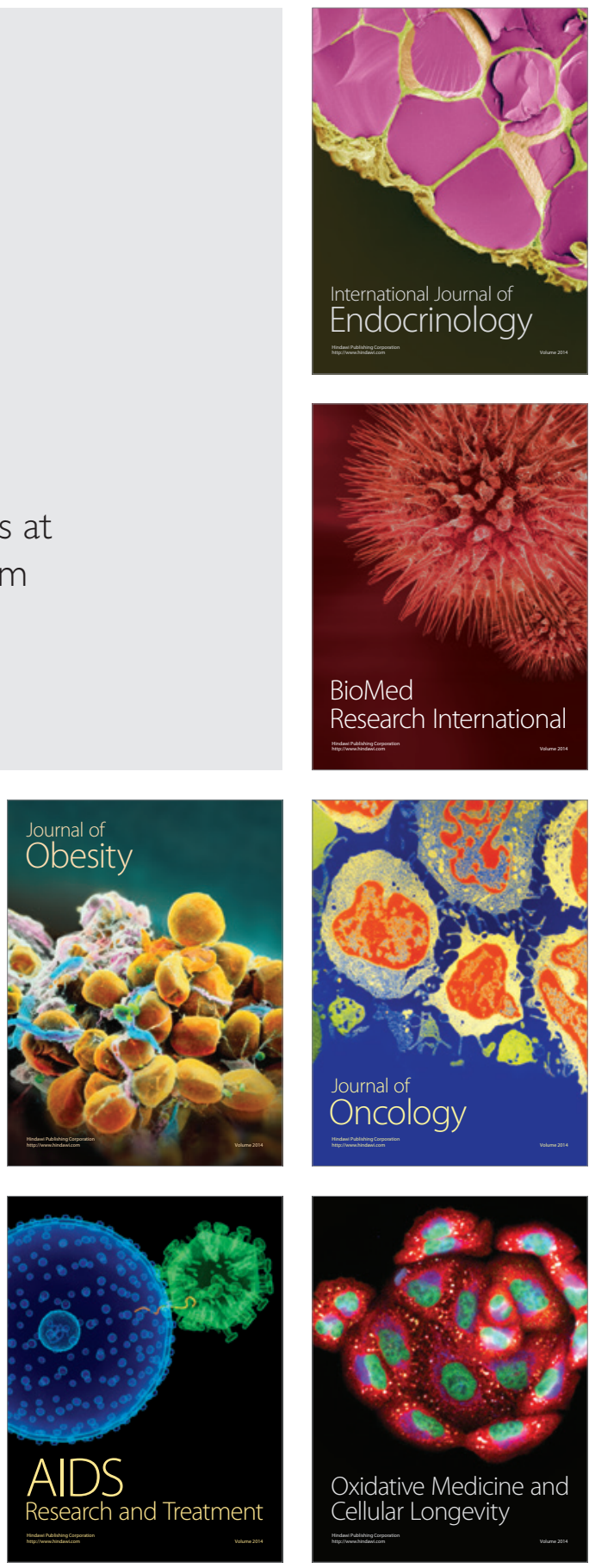